\title{
PLURALISMO JURÍDICO E \\ INTERCULTURALIDAD EN MÉXICO: LOS \\ JMELTSA'ANWANEJETIK Y LAS JUNTAS DE \\ BUEN GOBIERNO ZAPATISTAS
}

\section{LEGAL PLURALISM AND INTERCULTURALITY IN MEXICO: JMELTSA'ANWANEJETIK AND THE ZAPATISTAS COUNCILS OF GOOD GOVERNMENT}

\section{Lola Cubells Aguilar}

Universitat Jaume I, Castellón de la Plana, España

dcubells@uji.es

Recibido: mayo de 2019

Aceptado: diciembre de 2019

Palabras clave: justicia, indígenas, interculturalidad, pluralismo, colonialidad.

Keywords: justice, indigenous, interculturality, pluralism, coloniality.

Resumen: Existen en México diversas experiencias de justicias indígenas que se revitalizan, resisten y compiten con el Estado. Analizamos las Juntas de Buen Gobierno zapatistas y los arregladores de conflictos tseltales jmeltsa'anwanejetik-, procesos con semejanzas y divergencias que conviven en el estado de Chiapas. Conocer cómo se concibe la justicia indígena nos permite desvelar la diversidad epistemológica existente y visibilizar maneras otras se ser-estar-pensar- nombrar y habitar la vida. La reconstrucción del tejido social y la búsqueda de armonía son parte de las raíces de las justicias indígenas, guardianas de ecología de saberes.

Abstract: Diverse experiences of indigenous justice exist in Mexico and revitalize, resist and compete with the State. We analyze the Zapatistas Councils of Good Government and the tseltal conflict settlers -jmeltsa'anwanejetik-, processes with similarities and divergences that coexist in the state of Chiapas. Understand how indigenous justice is conceived it allows us to reveal the existing epistemological diversity and to make visible other ways of being-beingthinking-naming and inhabiting life. The reconstruction of the social bonds and the search for harmony are part of the roots of the indigenous justices, guardians of knowledge ecology. 
Para todos la luz, para todos todo

Cuarta Declaración de la Selva Lacandona

(EZLN,1996)

\section{l. Introducción}

\section{1.l. México: paradigma de la pluriversidad que resiste frente a la querra}

Múltiples latitudes nos muestran la deshumanización que conlleva el sistemamundo capitalista que habitamos. Si hay una, donde podemos radiografiar no solo el desgarro sino también la diversidad de luchas por la vida, es la correspondiente al territorio de México. La desaparición de 43 estudiantes de Ayotzinapa en 2014 se ha convertido en paradigma del patrón de desapariciones forzadas en México, perpetradas por el crimen organizado con la connivencia de instituciones y cuerpos de seguridad del Estado (Cubells, 2018). Ayotzinapa visibilizó al país como un narcoestado, evidenciando la falta de voluntad e incapacidad para investigar lo sucedido así como los vínculos de conexión entre los diferentes cuerpos de seguridad, incluidos el ejército, y el crimen organizado. Todo ello desveló una realidad sufriente para las mayorías pero oculta por los destellos del México "mágico y turístico". Existen otros muchos más casos, no tan visibilizados, como Tlatlaya (2014), Apatzingán (2015) o Tanhuato (2015) donde se produjeron graves violaciones de derechos humanos -torturas, ejecuciones extrajudiciales y desapariciones forzadas - cometidas por policías federales, fuerzas armadas y marina (CIDH, 2015:110-113).

En abril de 2019, la Alta Comisionada de las Naciones Unidas para los Dere- chos Humanos, Michelle Bachelet, visitó México. Pese a reconocer que si bien Ayotzinapa había revelado al mundo la escalofriante realidad de 40.000 personas desaparecidas (desde 2006), más de 850 fosas clandestinas existentes en el país y 26.000 cuerpos registrados sin identificar, reconoció que estaba sorprendida: "México tiene cifras de muertes violentas propias de un país en guerra"-sentenció- (Leticia, 2019). Esta es una realidad sangrienta denunciada por las organizaciones y personas defensoras de derechos humanos, intelectuales comprometidos y por supuesto, por quienes se llevan la peor parte, los pueblos originarios que siguen recibiendo megaproyectos asesinos, militarización y discriminación estructural en sus propios hábitats.

Para definir esta realidad me he apropiado del título de una serie de conferencias que el Observatorio Latinoamericano de Geopolítica (OLAG) de la Universidad Nacional Autónoma de México (UNAM) realizó en 2015, justo para analizar la "catástrofe nacional": "México: la guerra que no dice su nombre". Una guerra silenciada por gobernantes y medios de comunicación masivos, pero que tiene cifras que le dan rostro y veracidad. El Índice de Paz en México de 2019 (Institut for Economics \& Peace, 2019) arroja datos duros sobre la violencia que desgarra México: En 2018 hubo un recrudecimiento de las tasas de homicidios acompañada de una elevada tasa de impunidad (97\%). Estas cifras significan que solo en el $7 \%$ de delitos se abrió una investigación y únicamente un $3 \%$ de las investigaciones abiertas terminaron en sentencia. Dentro de los estados de México más pacíficos (es decir, con menos niveles de violencia) está Chiapas, aunque, pese a ello, el informe apunta que se experimentó un incremento de las tasas de homicidio durante 2018. 
México es paradigma no de un "Estado fallido", como dicen algunos, sino modelo de la reconfiguración del papel de los Estado-nación al servicio de los intereses capitalistas de las empresas transnacionales (ETN), entendiendo como tales, también, a los cárteles del narcotráfico. El profesor Pablo González Casanova, en su reciente artículo "¿A dónde va México?”, disecciona el entramado del poder político y económico del crimen organizado:

el crimen organizado combina sus conocimientos políticos con los económicos, y todos con los criminales y tecnológicos. Participa así en la dominación de un mundo en que se exige la práctica de la normativa moral en los tratos interpares de accionistas y de grandes propietarios, en que al mismo tiempo se urden medidas de especulación y depredación, que estructuran en el propio siglo XXI nuevas formas de acumulación primitiva, despojo, así como, de esclavismo, de servidumbre, de tributación y de salarios o ingresos de hambre que en gran parte del mundo pesan sobre la inmensa mayoría de una población a la que habiendo despojado de sus tierras y territorios, dejan en plena miseria, sin asomo de trabajo y sin los más elementales recursos para vivir, para comer, beber, curarse o enterrar a sus muertos. De tales hechos -difíciles de contar y de escuchar - proviene el éxodo más impresionante de la historia humana, un éxodo global en que muchos son los que mueren al atravesar selvas, desiertos y mares (González Casanova, 2019).

Como afirma Boaventura de Sousa Santos, vivimos una época en que la apariencia de los Estados esconde la realidad de un "fascismo social" emergente (Santos, 2004:22-28).

La defensa de los derechos humanos y de los pueblos nos exigen, ante dicha realidad, la necesidad de superar una mirada estatalista, positivista y jurídica de los mismos.
El nuevo sexenio iniciado en diciembre de 2018 con Andrés Manuel López Obrador, dirigente del Movimiento por la Regeneración Nacional (MORENA), viene acompañado de una elevada legitimidad popular, sin duda motivada por el deseo de acabar con tanta violencia sembrada. Y esta cuestión sí nos lleva a una de las grandes contradicciones del paradigma eurocéntrico, positivista y estatalista de los derechos humanos: ¿Cómo solicitarle al Estado que sea garante de los derechos humanos cuando las instituciones competentes están deslegitimadas, corrompidas y, en muchas ocasiones, son las que han provocado activa o pasivamente dichas vulneraciones?

En cambio, los pueblos originarios, quienes llevan resistiendo siglos a la colonialidad en sus diferentes vertientes y rostros, al margen del Estado y pese a él, nos enseñan su camino de supervivencia (que en sí ya es una gran hazaña) y las defensas de sus modos de vida que si bien son traducidos a conceptos hegemónicos como derechos colectivos o derechos de los pueblos indígenas nos demuestran que "otros mundos ya existen" (Correas, 2007). Solo debemos aprender a escuchar y quitarnos el miedo a dialogar para que las luchas anticapitalistas, antipatriarcales y anticoloniales se puedan dar la mano ante la crisis civilizatoria que atravesamos.

\subsection{Chiapas: la lucha es por la vida y contra la hidra capitalista}

La Selva Lacandona se ha convertido en un referente de los movimientos anticapitalistas o antisistémicos ${ }^{1}$. La organización

1. El concepto de "movimientos antisistémicos" fue acuñado por Immanuel Wallerstein en los años 70 para aglutinar, bajo un mismo término, dos tipos de movimientos populares: los movi- 
indígena zapatista que apareció ante el mundo como Ejército Zapatista de Liberación Nacional (EZLN) el 1 de enero de 1994 zarandeó al país entero así como a otros muchos corazones del mal llamado "mundo desarrollado". En estos 25 años de vida pública no solo han conseguido denunciar el colonialismo interno y neocolonialismo que sufrían y sufren los pueblos originarios sino también regalarnos un marco de interpretación del neoliberalismo para repensar las estrategias de construcción de movimientos antisistémicos (Wallerstein, 2003). El EZLN consiguió inyectar, a través de los "comunicados del Subcomandante Marcos", una poética revolucionaria dirigida a construir "otro(s) mundo(s) posible(s)". Es importante recordar que las y los zapatistas convocaron y celebraron en su territorio el Primer Encuentro Intercontinental por la Humanidad y contra el Neoliberalismo en 1996. Todavía hoy el movimiento sigue siendo un referente de las praxis transformadoras pero también del pensamiento crítico global ${ }^{2}$. A todos nos cautivaron los personajes salidos de la pluma del finado

mientos "sociales" (partidos socialistas y sindicatos) y los movimientos "nacionales" (creación de estados-nación por integración o secesión). En la actualidad, tal y como lo empleamos en el texto, se refiere a los movimientos llamados "antiglobalización", cuyo objetivo principal es luchar contra las consecuencias perversas del neoliberalismo. Bajo este concepto caben una gran cantidad de movimientos sin una estructura determinada que intentaron aglutinarse en torno al Foro Social Mundial ( a principios del siglo XXI) y si bien ello permitió visibilizar y dinamizar un ciclo de protestas, su excesiva burocratización, elitización y cooptación por parte de las ONG's minimizó su impacto y su vigencia actual.

2. En enero de 2019 más de 700 intelectuales y activistas del mundo enviaron una carta de solidaridad con la autonomía zapatista. Entre sus firmante: Ignacio Ramonet, Arundathi Roy, Sil-
Subcomandante Marcos ${ }^{3}$, por ejemplo, Don Durito de La Lacandona -un escarabajo andante- que impartía clases de economía política y neoliberalismo.

Como muestra, en 1999 apareció el texto "¿Cuáles son las características fundamentales de la IV Guerra Mundial4?". Dicho texto caracterizaba el ciclo contemporáneo como la IV Guerra Mundial, aquella en la que se construye un mundo unipolar dirigido a conseguir la "globalización" fundamentada en el "neoliberalismo". En este caso, el enemigo a destruir sería la humanidad entera: "Lo que importa es la ley del mercado y la ley del mercado marca que: tanto produces, tanto vales, tanto compras, tanto vales. La dignidad, la resistencia, la solidaridad estorban" (Marcos, 2017:161).

Quisiera destacar cómo el portavoz del EZLN ha sido capaz de vislumbrar cómo iban a operar las estrategias de guerra, alejadas del modo convencional. En la actualidad, vivimos una "guerra de espectro completo", utilizando el concepto propuesto por Ana Esther Ceceña, directora del OLAG. No hay solo dos partes en conflicto y no se utiliza únicamente la estrate-

via Federici, Raúl Fornet-Betancourt o Walter Mignolo (Vargas, 2019).

3. El Subcomandante Marcos murió el 25 de mayo de 2015 y nació el Subcomandante Galeano, tomando así el maestro zapatista apodado Galeano asesinado por un grupo paramilitar en la comunidad zapatista de La Realidad en la Selva Lacandona. Puede leerse el comunicado "Entre la luz y la sombra", 25 de mayo de 2015.

4. En este texto, el Subcomandante Marcos afirma que la llamada "Guerra Fría" sería la III Guerra Mundial iniciada en los años ochenta con el derrumbe del campo socialista de la Unión Soviética y prolongada hasta inicios de los años noventa, momento en el que se vislumbraría la IV Guerra Mundial. 
gia militar. Como sentencia el EZLN: “(...) las guerras del siglo XXI van a ser en contra de los que quieran ser diferentes. Frente a los que se resisten a desaparecer como diferentes, cada vez más se va a atentar contra sus derechos colectivos, cuidando el respeto de los derechos humanos individuales (Marcos, 2017:180)".

Desde su propio proceso de construcción no solo de una resistencia antisistémica sino de un proceso de lucha por construir un modo alternativo de vida -desde la elección de sus autoridades mediante el mandar obedeciendo, a la producción agroecológica o la construcción de los sistemas de salud y educación autónomos - han seguido describiendo y perfilando el sistema de muerte capitalista. Entre los días 3 y 9 de mayo de 2015, el EZLN convocó al Seminario "El pensamiento crítico frente la Hidra Capitalista" ${ }^{5}$ que partía de asumir que el sistema dominante actual es el capitalismo y que este domina no solo en una aspecto de la vida social sino que, como el animal mitológico, tiene múltiples cabezas: "si cortas una renacen dos y una de ellas es como su corazón". Explicaban que hay otra hidra que sin llegar a morir, se adapta, muta y es capaz de regenerarse completa desde una de esas partes. De ahí que, desde su mirada, la crisis terminal del capitalismo anunciada por Immanuel Wallerstein sea difícil de aceptar y sea más necesario estudiar cómo se comporta la Hidra Capitalista para poder establecer estrategias de defensa y construcción de otro sistema que cuide la vida y no la muerte.

5. Se puede consultar el programa y algunas de las intervenciones en: http://enlacezapatista.ezln. org.mx/2015/04/30/programa-y-otras-informaciones-del-homenaje-y-seminario/
Este movimiento también se ha caracterizado por la presencia activa de mujeres milicianas pero también por asumir la lucha de las mujeres como parte central de su estrategia de transformación. Fruto de décadas organizativas, las mujeres zapatistas nos invitaron, en marzo de 2018, a participar en el Primer Encuentro Internacional político, artístico, deportivo y cultural de las Mujeres que Luchan. Allí, más de 5000 mujeres diversas tomamos un compromiso: "acordamos vivir, y como para nosotras vivir es luchar, pues acordamos luchar cada quien según su modo, su lugar y su tiempo" (EZLN, 2018).

Enlazando el zapatismo con el tema principal que nos convoca: "Derechos Humanos y Globalización", coincido con el EZLN en la necesidad de tener claro que no se puede entender ni explicar el sistema capitalista sin el concepto de guerra (Marcos, 2017:275). Y no podemos analizar teóricamente ni luchar por los derechos humanos individuales y colectivos sin un análisis de este sistema dominante capitalista, racista, coIonialista y patriarcal. La defensa de los derechos humanos debe entenderse, parafraseando a Joaquín Herrera Flores, como la defensa de "los procesos antagonistas al capital que abren o consolidan espacios de lucha por la dignidad humana" (Herrera Flores, 2005:248) y, yo me permito añadir, de luchas por el "buen vivir". Asumiendo, como él decía, que debemos entender que existen diferentes maneras de enteder la dignidad y ampliándolo a re-conocer las pluriversas formas de entender la persona o el ser humano, abriendo la puerta a dialogar con esas otras maneras de ser-sentirpensar-habitar o nombrar la buena vida o la vida en plenitud. 


\section{Metodología}

\subsection{Crítica a las investigaciones extractivistas}

La crisis civilizatoria también atañe a las Ciencias Sociales y a las metodologías de investigación. Los propios movimientos indígenas han denunciado seguir siendo tratados como "objetos" y han denunciado las investigaciones "extractivistas". Esta crítica ha sido duramente realizada por el movimiento zapatista pero también desde otros procesos, hastiados de personas investigadoras llegadas desde sitios lejanos que extraen sabiduría y no vuelven a aparecer jamás. De ahí que el EZLN haya también debatido y discernido mucho sobre el ¿para qué? de la teoría. En el comunicado titulado "Chiapas: la treceava estela", en el que anunciaba la transformación de los Aguascalientes en Caracoles y el nacimiento de las Juntas de Buen Gobierno, explicaba que estas servirían, entre otras cosas, para que existiera una relación directa, sin intermediarios, entre los MAREZ y la sociedad civil nacional e internacional. Entre otras cuestiones, servirían para quienes quisieran presentar proyectos o investigaciones, explicitando que estas deberían tener beneficios para las comunidades (EZLN, 2003).

En la Primera Declaración de Barbados ${ }^{6}$ (1971) indígenas y antropólogos denunciaron el papel de la antropología en la dominación colonial. Después, la Investigación-Acción Participativa de Fals Borda (Colombia) o la Pedagogía del Oprimido de Freire (Brasil) han representado

6. Resultado de la reunión de antropólogos en el "Simposio sobre la Fricción Interétnica en América del Sur", celebrada en Barbados los días 25 al 30 de enero de 1971. guías transformadoras que cuestionaron las metodologías sujeto-objeto y propusieron maneras de enseñar a aprender o investigar, críticas y que han resultado las semillas de las propuestas metodológicas decoloniales actuales. Más recientemente, autores y autoras situadas en posicionamientos decoloniales han realizado investigaciones desde la metodología de "co-labor" o "colaborativa", es decir, aquella en la que diferentes actores sociales laboran juntos para llevar a cabo la investigación, para que ésta sea de utilidad para todos los involucrados y no sólo para la academia. Esta exigencia requiere, por tanto, establecer una relación otra con las personas, colectivos o movimientos que conforman parte de la investigación y como señala Xóchitl Leyva: "la creación de formas nuevas de relación entre la investigación social-académica-científica y la acción política" (Leyva, 2008:176).

\subsection{La investigación de co-labor en Chiapas}

Los resultados de la investigación que aquí muestro son parte de mi labor académica y también de mi trabajo como defensora de derechos humanos. Haber compaginado, durante años, la labor de observadora internacional de derechos humanos y la investigación me permitió conocer la realidad chiapaneca y participar de eventos y entrevistas con las Juntas de Buen Gobierno. Por otro lado, la realización de la tesis doctoral apostando por una metodología de co-laboración con la Misión Jesuita de Bachajón para fortalecer el sistema jurídico tseltal y los cargos comunitarios encargados de resolver conflictos, dotan a este trabajo de una mirada privilegiada sobre la defensa de los derechos desde el "caminar 
preguntado"7 -apropiándonos de la terminología zapatista-.

Durante mi trabajo como analista y observadora internacional de derechos humanos pude estar presente en el nacimiento de los Caracoles (2003) y realizar diferentes visitas e intercambios con las Juntas de Buen Gobierno. Además, el seguimiento bibliográfico permite conocer varias obras fundamentales sobre la justicia autónoma, particularmente, las investigaciones de Paulina Fernández (2014), Giovanna Gasparello (2018) y Mariana Mora (2018).

La parte correspondiente al Sistema Jurídico Tseltal es fruto del trabajo de campo realizado desde 2009 a 2012 colaborando con el proceso de formación de los jmeltsa'anwanejetik -arregladores de conflictos - pudiendo participar como asesora, pero también compartiendo, dialogando y realizando entrevistas formales e informales.

Este tipo de investigaciones se enmarcan en el esfuerzo de personas investigadoras-académicas dispuestas a caminar hacia un cambio de las relaciones entre la investigación social-académica-científica y la acción política que Xóchitl Leyva prefiere denominar "en búsqueda de la descolonización", de forma más humilde y realista. Y dan continuidad a las "Reflexiones sobre la práctica de una investigación descolonizada" lanzadas por el antropólogo Charles Hale (Hale, 2008). En dicho texto, Hale advierte que la investigación descolonizada parte de reconocer en pri-

7. “(...) aprendieron los hombres y mujeres verdaderos que las preguntas sirven para caminar, no para quedarse parados así nomás. Y, desde entonces, los hombres y mujeres verdaderos para caminar preguntan, para llegar se despiden y para irse saludan. Nunca se están quietos" (Marcos, 1994). mer lugar que "el investigador es un actor social posicionado. Tiene género, cultura y perspectiva política propia, ocupa una posición determinada en las jerarquías raciales nacionales y transnacionales" (Hale, 2008:299). No significa-aclara Hale- que la investigación y los actores políticos tengan una misma posición, por el contrario, matiza la necesidad de ocupar diferentes esferas y de no invisibilizar las tensiones inevitables y existentes. En este sentido, el/la investigador/a debe mantener su espacio propio, lo cual no debe impedir la existencia de diálogo y alianzas. Y enfatiza que "la investigación descolonizada se justifica por tener el potencial de rendir una mayor comprensión analítica y hasta novedosos acercamientos teóricos en relación al tema dado" (Hale, 2008:306). Desde esta perspectiva, lo más relevante no es sólo el producto final de la investigación, sino el mismo proceso, como una forma de cambiar las relaciones entre los participantes de la misma.

La academia debería contribuir a la emancipación de la sociedad, asumirse como un instrumento de emancipación. Como afirma Mariana Mora: "si existe una relación inmanente entre el conocimiento y el poder, entonces la investigación en sí se convierte en un terreno contencioso de posible transformación social y de cuestionamiento político" (Mora, 2018: 65).

Debe existir, por tanto, un compromiso vital para poder 'acompañar' un proceso y para que la investigación revierta en ambas partes, dejando atrás las investigaciones extractivistas. Así, la "pregunta epistémica, ética y política" que deberíamos hacer al iniciar una investigación -enuncia Xóchitl—tendría que ser: “investigar para qué, para quién y cómo?" (Leyva, 2008:205). 


\section{Resultados}

\section{I. Autonomías indígenas: el sistema jurídico tseltal y la justicia autónoma zapatista}

Desde este marco de guerra y esperanza esbozado, quisiera exponer dos experiencias de lucha por los derechos indígenas, desde el aporte de los pueblos originarios y ese regalo a la filosofía política que son los derechos humanos colectivos, entendidos como la manera de traducir su propia manera de pensar-sentir la vida y las relaciones entre persona-comunidad-madretierra-cosmos. Defiendo que al hablar de "derechos indígenas" debemos tener claro que se trata de una traducción de parte de su filosofía de vida al lenguaje imperial jurídico, sin que ello signifique que hayamos des-velado su manera propia de nombrarsentir-pensar y habitar su buen vivir.

El zapatismo visibilizó para muchos una realidad inexistente en un México deslumbrado por la posibilidad de formar parte del "mundo desarrollado" a partir de la firma del Tratado de Libre Comercio con Estados Unidos y Canadá, vigente a partir del 1 de enero de 1994. Los invisibles, los condenados de la tierra -en palabras de Fanon-aguaron la fiesta al México de arriba y recordaron que en el país existían personas que seguían siendo tratadas como esclavas en las fincas y cuyas vidas "valían menos que un pollo".

8. Las tierras donde nos recibieron las "compas" zapatistas en el Primer Encuentro de Mujeres que Luchan fueron, antes del levantamiento zapatista de 1994, de una familia finquera chiapaneca, conocida por su visceral racismo. Constantino Kanter se hizo famoso por su virulencia contra las comunidades indígenas alzadas y porque llegó a decir: "en Chiapas vale más un pollo que un in-
La autonomía indígena, esto es, la libre determinación para elegir sus propias autoridades, ejercer su justicia, crear sus propios sistemas de salud y educativo, tener medios de comunicación que respondan a sus intereses, defender su lengua y sus maneras propias de expresar su cosmovisión, se convirtió a partir de los Diálogos de paz entre el gobierno mexicano y el EZLN en una de las estrategias de lucha a nivel nacional de los pueblos originarios aglutinados dentro del Congreso Nacional Indígena (CNI).

Las comunidades zapatistas iniciaron la construcción en su territorio de los Ilamados Municipios Autónomos Rebeldes Zapatistas (MAREZ) -superpuestos a los municipios constitucionales-y gobernados por sus autoridades comunitarias elegidas a través de asambleas. Poco a poco fue desarrollándose una autonomía integral que abarca prácticamente todos los aspectos de la vida cotidiana. En agosto de 2003, y tras ver la imposibilidad de que el estado mexicano reformara la Constitución para dar cabida a la autonomía indígena, dieron un paso más creando otro piso autonómico, naciendo así los cinco Caracoles Zapatistas: centros políticos y culturales correspondientes a las cinco zonas zapatistas. En dichos Caracoles se conformaron las Juntas de Buen Gobierno: comités de representantes de los Consejos Autónomos de cada municipio para poder abordar aquellos problemas que superan el ámbito municipal y que requieren de una coordinación superior. Se convirtieron también en la cara visible del movimiento con la sociedad civil nacional e internacional y en el espacio donde impartir justicia y resolver conflic-

dio". Precisamente, en esas tierras "recuperadas" por zapatistas a la familia Kanter tuvo lugar el encuentro de "Mujeres que Luchan". 
tos no resueltos o complejos que superan el ámbito de los Consejos Autónomos? .

El movimiento zapatista ha convivido y convive con otros procesos organizativos "hermanos", en el sentido de haber compartido en el pasado los caminos de resistencia y de lucha que condujeron a la rebelión armada de 1994.

La pastoral liberacionista de la Diócesis de San Cristóbal de Las Casas, dirigida desde los años 60 por el obispo Samuel Ruiz, desató procesos teológicos y políticos que propiciaron transformaciones profundas en las comunidades indígenas chiapanecas. El Primer Congreso Indígena de 1974, organizado desde la Diócesis, permitió el encuentro personal entre los principales pueblos originarios de Chiapas (tseltales, tsotsiles, ch'oles y tojolabales) generando el nacimiento de un movimiento indígena independiente del Estado y también animando el cuestionamiento de las estrategias evangelizadoras aculturadoras. Esto provocó, por un lado: el inicio de la creación de una Iglesia Autóctona, impulsando la teología india y una red de diáconos indígenas recreada sobre la filosofía de los cargos-servicios comunitarios. El fortalecimiento de la organización política y económica que surgió como uno de los acuerdos del Congreso de 1974 favoreció la invitación, por parte de la Diócesis, de grupos maoístas que les apoyaran en la lucha de liberación (Cubells, 2016:159172). Estos procesos se vivieron de manera diferente en cada una de las regiones indígenas pero en todas ellas, unas primando la revitalización de la identidad indígena y otras, apoyando la organización

9. Cada MAREZ tiene su Consejo Autónomo. Una o dos personas de cada uno de los Consejos Autónomos de un Municipio conforman cada una de las Juntas de Buen Gobierno en las cinco zonas autónomas. democratizadora y política desarrollaron metodologías participativas que, como dicen las mujeres zapatistas les permitieron "abrir los ojos", no como resultado de las ideas externas que les enseñaban, sino como un "despertar, resultado de un proceso detonado y logrado entre ellas mismas derivado de los impulsos de autoreflexión colectiva" (Mora, 2018:207).

Podemos decir que se disgregaron dos procesos (no únicos) que son a los que nos vamos a referir en este trabajo: por un lado, la zona de la Selva donde la Misión Dominica adoptó una estrategia que primaba lo político sobre lo pastoral y donde las comunidades indígenas renovadas ${ }^{10}$ conformarán los principales bastiones del EZLN. Por otro lado, la zona de influencia de la Misión Jesuita de Bachajón desarrollará profundamente el proyecto de la Iglesia Autóctona y la revalorización de la cultura tseltal. En esta zona se desarrollará otro tipo de lucha por la defensa de los derechos indígenas, amparada por la Diócesis y donde la Palabra de Dios en clave liberacionista tiene una profunda huella en todo su proceso.

En este marco de lucha y defensa de los derechos indígenas quisiera mostrar tam-

10. Las comunidades de la Selva fueron creadas ex novo por la huida de las comunidades de origen (Altos y Norte) bien por la falta de tierras, o bien porque escapaban de la situación de esclavitud que sufrían en las fincas. El "éxodo a la Selva" permitió abrir la frontera agrícola sin necesidad de realizar reparto agrario. Allí llegaron personas pertenecientes a diferentes pueblos originarios: tseltales, tsotsiles y ch'oles y conformaron nuevas comunidades que fueron el semillero perfecto en el que fructificaron las ideas liberacionistas, la resistencia indígenas y, posteriormente, la lucha marxista llegada desde las Fuerzas de Liberación Nacional (FLN): una guerrilla nacida en los años 60 y que será el germen del EZLN (Cedillo, 2008). 
bién la diversidad de procesos que en los propios territorios indígenas existen. En ambos, la recuperación del derecho propio -en palabras de Jesús de la Torre "el derecho a decir su derecho" (Rosillo y De la Torre, 2009) — forma parte de ambos procesos de autonomía. En la zona tseltal de la Misión Jesuita, después del levantamiento armado y en particular, ante la Guerra de Desgaste Integral ${ }^{11}$ desatada en el territorio, recuperaron las maneras propias de resolver conflictos como una manera de buscar la paz en sus territorios y suplir la ausencia del Estado así como la instrumentalización colonial que el Estado realiza de la justicia y el derecho.

La cuestión que quisiera destacar al hablar de estas dos experiencias de justicias indígenas es, sobretodo, cómo pueden ser maneras de visibilizar otras maneras de expresar el buen viviry cómo se relacionan con la gramática moral de los derechos humanos. No debemos olvidar que ambos procesos de autonomía se desarrollan en territorios militarizados, donde actúan grupos narco-paramilitares y donde los megaproyectos de despojo (carreteras, minería o centros ecoturísticos) son los rostros de la hidra capitalista a la que se enfrentan.

\subsection{Las Juntas de Buen Gobierno: la justicia del mandar obedeciendo}

La resolución de conflictos en el territorio zapatista se realiza desde el nivel más bajo de la autonomía, desde las comunidades;

11. Es definida como una guerra realizada por sucesivos operativos puntuales que van asfixiando al enemigo en los terrenos político, económico, y militar. Es un concepto psicosocial utilizado como alternativa al término militar "guerra de baja intensidad". si el conflicto afecta a varias comunidades o no se pueda resolver a nivel comunitario pasa al Consejo Autónomo del MAREZ y, en última instancia, y siempre que afecte a conflictos entre personas pertenecientes a diferentes organizaciones compete a las JBG. Los tres libros antes mencionados y, en particular, el de Gasparello (2018) y Fernández (2014) recogen testimonios y explican con detalle cómo funciona esta justicia. Mariana Mora (2018) también habla desde la experiencia del Caracol IV Morelia.

La resolución de conflictos se lleva a cabo sobre todo para resolver temas agrarios, familiares, aunque también conocen del tráfico ilegal de personas o recursos naturales. En fin, de cualquier infracción de las normas zapatistas. A la justicia zapatista acuden zapatistas pero también miembros de otras organizaciones indígenas y también personas no indígenas que valoran la "gratuidad" del servicio frente a una justicia estatal corrupta y materialista. Un caso paradigmático interesante que escuché entrevistando a la JBG y es recogido por Giovanna Gasparello fue la detención de un pollero ${ }^{12}$-en territorio zapatista está prohibido el tráfico de drogas, personas y maderas preciosas, entre otras prohibiciones - y la sanción consistió en participar en la construcción de un puente como trabajo comunitario.

La justicia zapatista es calificada por Giovanna Gasparello como una justicia autónoma e intercultural: autónoma, porque es parte de un proceso más amplio diferenciado del sistema estatal; intercultural, porque es construida en colaboración

12. Pollero: "persona que transporta ilegalmente trabajadores indocumentados a otro país, generalmente a los Estados Unidos de América" según el Diccionario de americanismos. 
entre diversos pueblos y comunidades indígenas y no indígenas (Gasparello, 2018:233).

Dicha justicia está fundamentada en la reconciliación, la restitución del daño causado y la reeducación (Gasparello, 2018:233). Esta última cuestión es destacada por esta investigadora como una muestra de la capacidad de revitalización e innovación de las justicias indígenas. La justicia en las comunidades zapatistas forma parte del proceso de autonomía zapatista y de toda su organización fundada en el mandar obedeciendo. Sobre el sentido profundo de este principio zapatista me gustaría transcribir un testimonio que recoge la investigación de Mariana Mora (Mora, 2018:233):

Cuando uno es Consejo tiene que tener autoridad, no es sólo ser autoridad. Y para tener autoridad uno tiene que tener paciencia, respeto, querer aprender y escuchar. No fue voluntad propia que uno es autoridad, es porque el pueblo te elige. Hay que respetar al pueblo, no se puede rebasar. Dios, que también es la tierra y el pueblo, los eligió. No hay autoridades sin pueblo y sin pueblo no hay vida. De ahí el mandar obedeciendo.

El trabajo de las autoridades, a la hora de resolver un conflicto, se asemeja a la intermediación, aunque en casos en los que no se puede llegar a una solución amistosa o no se reconoce el daño causado se imponen sanciones, la mayoría de ellas consistentes en trabajos comunitarios.

La cuestión que quisiera destacar en esta experiencia, más allá de cómo se llevan a cabo la resolución de conflictos, es cómo esta justicia basada en la organización comunitaria, en los servicios a la comunidad gratuitos como los "cargos" y la construcción de una ética política beben de los diferentes caminos por los que las comunidades transitaron hasta el levantamiento armado que, sobretodo, en el caso de la Selva permitió la "toma de tierras", precisamente las que estaban en manos de finqueros $y$, con ello, el fin de la relación de subordinación frente al finquero-patrón. Mariana Mora entiende que el mandar obedeciendo subvirtió la ubicación naturalizada de las comunidades indígenas que lleva a dividir a la población local entre los que nacieron para gobernar y los que nacieron para obedecer (Mora, 2018:235). Como ella misma refleja, al compartir la evolución de su investigación realizada desde la propuesta de una metodología descolonizadora para "trascender los puntos ciegos epistemológicos", fue necesario introducir una cuestión a la que ella no le había dado la importancia merecida: las fincas en la historia local como una manera de ordenar racialmente a la sociedad. Este análisis, a partir de los testimonios recolectados, le permite afirmar que "(...) la formación política de las comunidades zapatistas, sobre todo para las generaciones que crecieron antes del levantamiento, se basa en parte en un rechazo a la figura del mozo" (Mora, 2018:105).

Por tanto, la justicia y las normas que surgen de la autonomía indígena formarían parte de la política kuxlejal. Mariana Mora señala que esta palabra tseltal traducida como "vida-existencia":

es tan sólo un punto de anclaje que adquiere sentidos cuando se relaciona con la vida en colectivo, stalel jkuxlejaltik, una forma de ser en el mundo como pueblo y como parte del término para la aspiración cotidiana de vivir con dignidad, lekil kuxlejal. El horizonte de lucha por lekil kuxlejal, con el término equivalente en tojolabal, sak'aniltik, como una forma digna del buen vivir se refiere no sólo a un ser individual, sino a ese ser en 
relación con un colectivo, que a su vez se vincula con la tierra, con los mundos natural y sobrenatural, que arropa y alimenta a los seres y, por tanto, debe ser honrado (Mora, 2018:38).

\subsection{Los jMeltsa'anwanejetik: la justicia de la armonía -jun pajal o'tanil-}

Desde la cosmovisión tseltal se considera que cuando existe en la comunidad un problema o conflicto (en tseltal, wocol), éste representa un desorden, una pérdida del equilibro que debe existir entre los seres humanos, la comunidad y el cosmos, es decir, una pérdida de armonía (en tseltal, jun pajal o'tanil-un solo corazón). Interpretan que cuando alguien comete un perjuicio contra otro es porque su corazón se ha ido, y por tanto, queda roto y dividido (cheb o'tanil-dos corazones). El diálogo y la resolución pacífica del problema, sin agresiones, persigue que el corazón de la persona que ha tenido un comportamiento negativo hacia otra y, por tanto, que ha roto la armonía no sólo personal, sino comunitaria, espiritual y cósmica, vuelva a estar en su sitio, en su casa (nacal o'tanil-el corazón está en casa, está tranquilo) y, de ahí, que vuelva a existir "un solo corazón"-jun pajal o'tanil, entre las personas enfrentadas. Este proceso se lleva a cabo a través de la reconciliación y el perdón (suhtesel o'tanil-regreso del corazón), no sólo entre las partes, sino hacia la comunidad. Sólo de este modo puede retornar la armonía al territorio comunitario, que es la forma de vivir en paz-smalil k'inal (vida en plenitud). La perturbación que genera un problema o conflicto se extiende a la comunidad entera, porque se piensa que al generar un malestar o cha- mel (enfermedad), ésta puede afectar a terceras personas.

El trabajo de reconciliación está encomendado a las Ilamadas "comitivas" de jueces y juezas, es decir, un trabajo colegiado basado en el servicio comunitario. Los y las jmeltsa'anwanejetik son hombres y mujeres indígenas, la mayoría de ellos/as sin haber tenido acceso a la educación formal, exceptuando los/las más jóvenes. En palabras del padre jesuita Pepe Avilés, los y las jmeltsa'anwanejetikarregladores/as de conflictos tienen como función: "rehacer el tejido social, bordar los corazones para reconstruir la armonía rota." (Grillenzoni, et al., 2012:5)

Los requisitos para poder desempeñar el cargo son: el nombramiento consensuado por la comunidad -basado en el íntimo conocimiento de los cargos-, ser una persona con vida irreprochable, la gratuidad, el acompañamiento del servidor por varias personas con autoridad moral, como consejeros (las comitivas) y la temporalidad del servicio (son elegidos durante 3 años). Como el resto de cargos comunitarios están guiados por el sentido de autoridad existente en la cultura tseltal. Como afirma el antropólogo jesuita, Eugenio Maurer, en la esencia del concepto de autoridad se encuentra "no la idea de poder mandar, sino al contrario, la de servir" (Maurer, 1984:79). Para evitar la pérdida de la experiencia y los conocimientos, debido a la rotación de los cargos, se utiliza el sistema tradicional de banquilal (hermano mayor)/ihts'inal (hermano menor). Primero se sirve como ihts'inal y después de tres años, se pasa a ser banquilal. Es, por tanto, rotativa y jerárquica. Para el historiador Jan de Vos, de esta manera, se crea "una continuidad escalonada, donde no se pierde la experiencia ni se generan 
grupos de poder" (De Vos, 2010:289). De este modo, la comitiva encargada de resolver los conflictos está compuesta por un banquilal, un ihts'inal, y un xuht' (el último) quien, como aprendiz, va conociendo cómo resolver los conflictos y el sistema jurídico tseltal desde la práctica. El cargo de xuht' está siendo ocupado por jóvenes, chicos y chicas, como una escuela de aprendizaje sobre su propia cultura. Cada comitiva elige a un secretario (ts'ihbaywanej), encargado de redactar las actas; y un Principal (Trensipal) que, aunque tradicionalmente había recaído en personas de reconocido prestigio por la cantidad de cargos que han desempeñado en su vida, vemos que en el caso de los y las jmeltsa'anwanejetik no cumple tanto esa función sino la de "animar el corazón" de los jMelts'anwanejetik, lo que se traduce en vigilar su trabajo y controlar que persigan los valores de la armonía y la búsqueda de la verdad.

A diferencia de los Caracoles zapatistas, los y las jMeltsa'anwanejetik desbordan el ámbito comunitario y, en ocasiones, se convierten en asesores o intermediarios entre el Ministerio Fiscal y la persona denunciada o denunciante (según el caso). En otras ocasiones, al compartir territorio con la organización zapatista también han debido coordinarse con las autoridades autónomas para resolver conflictos entre un miembro zapatista y otro perteneciente a la Palabra de Dios. Es cierto que entre ambos, a pesar de las diferencias de adscripción, prima una mismo modo de entender la justicia en cuanto reconciliación y restitución, la gratuidad del servicio comunitario y la cultura.

En ambos casos estamos ante justicias que buscan "la raíz del problema", que son gratuitas, donde se intenta frenar los abusos y la corrupción. En las propias lenguas y recuperando los modos propios y desde la autodeterminación generando cambios que se adecuen a las necesidades actuales y también al sentipensar (Fals Borda) de las mujeres que demandan más presencia tanto asumiendo cargo-autoridad como resolviendo conflictos.

\section{Discusión}

\section{I. Justicias indígenas, derechos humanos y buen vivir}

Esta forma de entender la justicia tseltal, dialogada, en búsqueda de la armonía y la paz, lejos está de los tópicos creados en torno a las justicias indígenas como sinónimo de violación de derechos humanos y abusos múltiples. Uno de los argumentos más comunes en contra de reconocer y dialogar con las justicias indígenas es que la mayoría violan los derechos humanos y, en particular, los derechos de las mujeres indígenas.

Por el contrario, diversas investigaciones muestran que las mujeres indígenas se han convertido en sujetos clave para la reformulación de las "costumbres", en señalar qué costumbres son actuales y cuáles no, o en qué sentido la justicia debe respetar su propia manera de entender el respeto a la mujer. El comunicado de la comandante Esther, leído ante el Congreso de la Nación en México en marzo de 2001, argumentando a favor de una reforma constitucional que reconociera la autonomía indígena, desmontó, uno a uno, esos argumentos disfrazados de derechos humanos pero cargados de racismo y colonialidad:

Es la ley de ahora la que permite que nos marginen y que nos humillen. Por eso no- 
sotras nos decidimos a organizar para luchar como mujer zapatista. Para cambiar la situación porque ya estamos cansadas de tanto sufrimiento sin tener nuestros derechos. No les cuento todo esto para que nos tengan lástima o nos vengan a salvar de esos abusos. Nosotras hemos luchado por cambiar eso y lo seguiremos haciendo. Pero necesitamos que se reconozca nuestra lucha en las leyes porque hasta ahora no está reconocida. (...) Nosotras además de mujeres somos indígenas y así, no estamos reconocidas. Nosotras sabemos cuáles son buenos y cuáles son malos los usos y costumbres. Malas son de pegar y golpear a la mujer, de venta y compra, de casar a la fuerza sin que ella quiera, de que no puede participar en asamblea, de que no puede salir en su casa. Por eso queremos que se apruebe la ley de derechos y cultura indígena (...) quiere decir que queremos que sea reconocida nuestra forma de vestir, de hablar, de gobernar, de organizar, de rezar, de curar, nuestra forma de trabajar en colectivos, de respetar la tierra y de entender la vida, que es la naturaleza que somos parte de ella, en esta ley están incluidos nuestros derechos como mujer que ya nadie puede impedir nuestra participación, nuestra dignidad e integridad de cualquier trabajo, igual de los hombres (Esther, 2001).

La Comandanta Esther defendió la demanda de autonomía, no sólo como algo compatible con los derechos de las mujeres indígenas, sino como el canal necesario para su efectiva realización. Representa así una demanda de diversidad al interior de la diversidad. De este modo, el camino para garantizar los derechos de las mujeres indígenas no consiste en negar o limitar la autonomía, sino en reconocer las luchas de las mujeres al interior de las organizaciones y procesos indígenas, desde su propia cosmovisión, sin imponer miradas coloniales, ni siquiera las provenientes, de buena fe, desde los feminismos liberales y eurocéntricos. En este sentido, $\mathrm{M}^{\mathrm{a}}$ Teresa Sierra señala que el Estado no debe definir los límites al derecho indígena puesto que lo que hay que reconocer son los "espacios propios de discusión al interior mismo de los pueblos indígenas sobre temas vinculados con los derechos humanos, las costumbres y la violencia" (Sierra, 1997:138), fomentando así, una cultura de diálogo que permita conocer y argumentar el marco de los derechos humanos. Así entendida, la autonomía permite visibilizar los sentires, pensares y voces diversas de las mujeres indígenas. Sabiamente, la comandanta Esther, muestra los procesos internos de las mujeres indígenas, como sucede en el caso tseltal analizado, en el que reivindican sus costumbres, desde una perspectiva incluyente y cuestionan también la visión abstracta y homogeneizador de las tradiciones. Las jmeltsa'anwanej antsetik (mujeres arregladoras de conflictos) como las mujeres zapatistas defienden su cultura a través de la demanda de participación como autoridades en la resolución de conflictos. Estos procesos, donde las mujeres están aportando transformaciones profundas a las normativas indígenas, muestran cómo se están gestando propuestas emancipadoras de la cultura y la justicia, en donde lo colectivo no conlleva la opresión de los individuos, como apunta $\mathrm{M}^{\mathrm{a}}$ Teresa Sierra. Deberíamos así reconocer, como ejemplo de epistemologías insurgentes, aquellas que emanan de los procesos de las mujeres indígenas, ya que siguiendo a esta antropóloga mexicana, "las mujeres indígenas al cuestionar sus costumbres sin rechazar su cultura están cuestionando los paradigmas dualistas entre el univer- 
salismo y el particularismo de los derechos" (Sierra, 2015:25).

Es importante, por tanto, rechazar las imágenes "victimizadoras" hacia las mujeres indígenas, como si no tuvieran capacidad de organización y subversión, y que además, son utilizados para seguir invisibilizando y limitando las justicias indígenas, como opresivas de forma sistemática. Vemos, por el contrario, que esta línea de análisis de las justicias indígenas incorporando la perspectiva de género, permite ver cómo las mujeres indígenas dan un fuerte aliento a la transformación emancipadora del derecho indígena, y desecha las imágenes victimizadoras predominantes en algunas esferas y estudios sobre los derechos de las mujeres indígenas y los sistemas jurídicos indígenas.

Como señala $M^{a}$ Teresa Sierra, experta en reflexionar sobre las demandas de género en los sistemas normativos indígenas: "No se trata del reconocimiento de una cultura esencial, sino del reconocimiento del derecho a reconstruir, confrontar o reproducir una cultura, no en los términos establecidos por el Estado, sino en los delimitados por los propios pueblos indígenas, en el marco de sus propios pluralismos internos" (Sierra et. al, 2013:39). Las autoras del proyecto "Justicias indígenas y Estado" refiriéndose a otras realidades como las mujeres nahuas de los Juzgados Indígenas de Cuetzalan (Puebla), las promotoras de la Policía Comunitaria (Guerrero) o las alcaldesas mayas de Guatemala, apuntan que en estos procesos de autonomía indígena las mujeres:

teorizan sobre su cultura con perspectivas que rechazan las definiciones hegemónicas de tradición y cultura del indigenismo oficial y de los sectores conservadores de las organizaciones indígenas nacionales, mediante el planteamiento de la necesidad de cambiar aquellos elementos que excluyen y marginan a las mujeres (Sierra et al., 2013:39).

\subsection{Las justicias indígenas: maneras de visibilizar epistemologías del "buen vivir"}

Las justicias indígenas son zonas de contacto que demuestran tener capacidad para la reinvención, de ahí la crítica a referirse a ellas como simples "usos y costumbres" - a pesar de que muchos pueblos originarios sigan refiriéndose así a sus sistemas normativos-.

Señalo que en el caso del sistema jurídico tseltal hablamos de la justicia del corazón (Cubells, 2016) en cuanto busca regresar el corazón roto de la personacomunidad-madretierra-cosmos. Si smalil k'inal podría ser entendido como paz -0 según Antonio Paoli lekil kuxlejal- estamos diciendo que a través de la recuperación, revitalización y fortalecimiento de los sistemas de justicia propios representan una de las estrategias de resistencia comunitaria y de creación de relaciones de servicio comunitario en beneficio del buen vivir. Nosotras lo miramos como el cumplimiento de un derecho y los pueblos originarios como el restablecimiento del desequilibrio cósmico.

La defensa de las justicias indígenas, desde estas dos experiencias de autonomía indígena, no deben ser abordadas como una mera descentralización del poder judicial, tal y como algunas regulaciones pretenden, sino como expresión de una constelación de saberes y prácticas con- 
vertidas en "zonas de contacto"13 (Santos, 2009:582) que se convierten en semillero privilegiado para des-velar "epistemologías del sur" (Santos y Meneses, 2014) o epistemologías del "buen vivir" (Ceceña, 2013). Las "epistemologías del sur" se refieren a la diversidad epistemológica del mundo: son el conjunto de las intervenciones que denuncian la supresión de formas de saber propias de los pueblos y/o naciones colonizados, valoran los saberes que resistieron con éxito e investigan las condiciones de un diálogo horizontal entre conocimientos (Santos y Meneses, 2014:10). Ceceña, por otro lado, se refiere con "epistemologías del buen vivir" al:

campo semántico en el que pueden ser colocadas todas aquellas experiencias emancipatorias, particularmente del ocaso del siglo XX en adelante, que han construido imaginarios externos o dislocados con respecto a los pilares epistemológicos de la modernidad. Es decir, pensamientos-experiencias de lucha que apuntan hacia una bifurcación desde el sistema actual, despegándose de su modo de hacer y de entender el mundo (Ceceña, 2013: 99).

\section{Conclusiones}

1. El informe al que me he referido al inicio de este texto, el Índice de Paz en México de 2019, sin referirse a los pueblos originarios, lanza una conclusión sumamente interesante: "La cooperación comunitaria es muestra del nivel de Paz Positiva, puesto que es más probable que las comunidades que muestran altos niveles de coope-

13. Las zonas de contacto según Boaventura de Sousa Santos son campos sociales en los que diferentes mundos de la vida normativos se encuentran y chocan entre sí. ración resistan los embates negativos externos y se recuperen con más rapidez de los desafíos".

¿Podemos relacionar las experiencias de autonomía indígena, el control territorial y las prácticas políticas orientadas a la armonía, en el caso tseltal o kuxlejal -vida existencia? Esta cuestión que entendemos es difícil de probar desde nuestra investigación, es abordada por Giovanna Gasparello en su libro sobre justicias indígenas en Chiapas, relacionando justicia, violencia y autonomías, afirmando que "la autonomía puede ser una respuesta colectiva para desactivar la violencia y resolver los conflictos, ya que busca dialécticamente la transformación y el reequilibrio de las relaciones sociales" (Gasparello, 2018:25).

2. Si los pueblos originarios aprenden la lengua jurídica hegemónica como instrumento de resistencia, no basta con el "mero reconocimiento" desde el Estado sino que necesitamos asumir como parte de la cultura-filosofía jurídica del Estado y de sus instituciones estos modos de justicia y de democracia que muestran veredas descolonizadoras que se convierten en brújulas de alternativas sistémicas.

3. De este modo, respetar, fortalecer y renovar las justicias indígenas, implica defender constelaciones de conocimientos y prácticas subalternas, guardianas de epistemes y racionalidades otras que pueden abonar lo que Boaventura de Sousa Santos nombra como "cosmopolitismo insurgente y rebelde", donde la interculturalidad crítica y decolonial aparece como un requisito indispensable. Sin ser amante de las disyuntivas, comparto la 
planteada por Fornet-Betancourt, al afirmar como uno de los desafíos del presente: "interculturalidad o barbarie" (Fornet-Betancourt, 2006:39).

4. Debemos seguir denunciando la utilización colonial y hegemónica de los derechos humanos por parte del Estado en muchas ocasiones para criminalizar y reprimir el desarrollo de las justicias indígenas: ha pasado con la Policía Comunitaria y con las Juntas de Buen Gobierno. En menor medida con el sistema de justicia tseltal porque atiende conflictos de menor envergadura, pero también lo están sufriendo con su reivindicación de la libre determinació y el reciente nombramiento de su Gobierno Comunitario. Es un discurso reiteradamente utilizado e incluso asimilado desde las propias normativas utilizadas para fortalecer las justicias indígenas al establecer las claúsulas de derechos humanos como límite o condicionante de las justicias indígenas (Cubells, 2016:393). La falta de desarrollo legislativo y reglamentario encaminado a establecer pautas de diálogo intercultural o tribunales mixtos como los propuestos por Raquel Yrigoyen (1999) para dirimir conflictos competenciales o de interpretación y abonar el conocimiento sobre las justicias indígenas, indica que en México estamos lejos todavía de poder hablar de una justicia intercultural en la estructura del Estado y, por tanto, prevalece un pluralismo jurídico monista. André Hoekema define el pluralismo jurídico formal "unitario" como aquel en el que coexisten dos o más sistemas de derecho que a pesar de estar reconocidos formalmente, el derecho oficial mantiene la hegemonía sobre los demás, decidiendo uni- lateralemente su aplicabilidad y legitimidad. En cambio, en el pluralismo jurídico formal de tipo "igualitario" el derecho oficial reconoce la validez de las normas de otros sistemas jurídicos y desde su diferencia cultural estos se asumen como parte de del orden legal nacional. Este tipo de pluralismo exige la existencia de normas que regulen la relación entre los diferentes sistemas jurídicos que conviven, animando a la mutua intersección (Hoekema, 2002:70).

5. Las justicias indígenas son parte de la resistencia pacífica que reconstruye el tejido comunitario y como hemos visto son guardianas de sabidurías del corazón -sp'ijil o'tanil- que podríamos traducir como "filosofías". Desde estas sabidurías otras se reinterpretan los derechos humanos generando experiencias donde se puede escuchar hablar de lekil kuxlejal o jun pajal o'tanil pero también de derechos humanos, derechos indígenas y de la Palabra de Dios como guías de la vida.

6. Es momento de aplicar el "giro decoIonial" (Castro-Gómez y Grosfoguel, 2007) a los derechos humanos. Interpretarlos desde una perspectiva crítica y complejizada pero ante todo asumir que han convivido y conviven con otras maneras de ser-sentir-pensarnombrar y habitar el mundo que vienen de otras memorias de resistencia pero donde el diálogo intercultural se fragua en trincheras que siguen siendo marginadas desde los centros de conocimiento globales. No olvidemos como dice Ana Esther Ceceña que la "guerra de espectro completo" pretende acallar las resistencias de los dominados, no sólo a través de estrategias militares sino también cultura- 
les porque "(...) el lugar decisivo para prevenir y/o disuadir cualquier intento por modificar las reglas del juego o por construir diques al dominio capitalista y apagar la rebeldía, la disidencia o la insurgencia es el cultural, donde radican la memoria histórica, las cosmovisiones, las epistemes y las utopías" (Ceceña, 2006:36).

\section{Bibliografía}

Bartolomé, M. A. et al. (1971), "Primera Declaración de Barbados de 1971: Por la liberación del indígena" en Servindi. Disponible en: http://www.servindi.org/pdf/ Dec_Barbados_1.pdf [20 de septiembre de 2019]

Camacho, Zósimo (2019), "La lucha indígena de hoy, puede ser la última: Carlos González", Contralínea, Disponible en: https://www.contralinea.com.mx/archivorevista/2019/05/16/la-Iucha-indigena-dehoy-puede-ser-la-ultima-carlos-gonzalez/ [10 junio 2019].

Castro-Gómez, Santiago y Ramón Grosfoguel (eds.) (2007), El giro decolonial. Reflexiones para una diversidad epistémica más allá del capitalismo global, Colombia, Siglo del Hombre Editores/Universidad Central-Instituto de Estudios Sociales Contemporáneos y Pontificia Universidad Javeriana/Instituto Pensar, 2007.

Ceceña, Ana Esther (2006), "Sujetizando el objeto de estudio, o de la subversión epistemológica como emancipación", en Ceceña, Ana Esther, Los desafíos de las emancipaciones en un contexto militarizado, Buenos Aires, CLACSO, pp. 13-43. Cedillo, Adela (2008), El fuego y el silencio. Historia de las FPL, México, Comité 68 Pro Libertades Democráticas, A.C., 2008.
CIDH (2015), Situación de derechos humanos en México. Disponible en http:// www.oas.org/es/cidh/informes/pdfs/ Mexico2016-es.pdf [4 de junio 2019] Correas, Óscar (2007), Pluralismo jurídico. Otros horizontes, México, Eds. Coyoacán.

Cubells, Lola (2016), "La Justicia del Corazón-O'tan. Armonía y derechos indígenas desde la sabiduría tseltal en Chiapas: Descolonizando los derechos humanos, tejiendo interculturalidad", Tesis de Doctorado en "Derechos Humanos, Paz y Desarrollo Sostenible", Departamento de Filosofía del Derecho, Moral y Política, Universitat de València.

Cubells, Lola (2018), "Ayotzinapa: cuatro años buscando verdad y justicia" en El Salto. Disponible en: https://www.elsaltodiario.com/mapas/ayotzinapa-cuatroanos-buscando-verdad-justicia [5 de junio de 2019].

De Vos, Jan (2010), "Vino nuevo en cueros nuevos", en De Vos, Jan, Camino del Mayab. Cinco incursiones en el pasado de Chiapas, México, CIESAS.

EZLN (2003), "Chiapas:la treceava estela. Sexta Parte: un buen gobierno" en Enlace Zapatista, Disponible en: http://enlacezapatista.ezln.org.mx/2003/07/21/ chiapas-la-treceava-estela-sexta-parteun-buen-gobierno/ [18 mayo 2019].

EZLN (2018), "Palabras de las compañeras zapatistas de inicio del Primer Encuentro Internacional Político, Artístico, Deportivo y Cultural de Mujeres que Luchan" en Enlace Zapatista, Disponible en: http:// enlacezapatista.ezln.org.mx/2018/03/08/ palabras-a-nombre-de-las-mujeres-zapatistas-al-inicio-del-primer-encuentrointernacional-politico-artistico-deportivoy-cultural-de-mujeres-que-luchan/ [7 de junio de 2019]

Fornet-Betancourt, Raúl (2006), “Interculturalidad o Barbarie. 11 tesis pro- 
visionales para el mejoramiento de las teorías y prácticas de la interculturalidad como alternativa de otra humanidad" en Comunicación. Revista Internacional de Comunicación Audiovisual, Publicidad y Estudios Culturales, Issue 4, Sevilla, pp. 27-49.

Gasparello, Giovanna (2018) Justicias y pueblos indígenas en Chiapas. De la violencia a la autonomía, Ciudad de México, UAM-Tirant Humanidades.

González Casanova, Pablo ( 2019), "A dónde va México" en La Jornada. Disponible en: https://www.jornada.com.mx/ ultimas/2019/04/07/a-donde-va-mexicopablo-gonzalez-casanova-6475.html [8 de abril de 2019]

Grillenzoni, Elena, Lola Cubells y Marisela García (eds.) (2012), Manual de Derecho Indígena. Desde la experiencia de reconciliación y justicia tseltal, México, CEDIAC/ Misión de Bachajón.

Gómez, Rosalba (2010), "Jurisdicción indígena y acceso a la justicia" en Revista Aquí estamos. Derechos indígenas en México: luchas y actores, enero-julio, 7(12), México, pp. 37-49.

Hale, Charles (2008), "Reflexiones hacia la práctica de una investigación descolonizada" en Anuario 2007 del Centro de Estudios Superiores de México y Centroamérica,Chiapas, CESMECA, pp. 299-316.

Herrera Flores, Joaquín (2005), Los derechos humanos como productos culturales. Crítica del humanismo abstracto, Madrid, La Catarata/IPES ELKARTEA.

Hoekema, André (2002), "Hacia un pluralismo jurídico formal de tipo igualitario". Pluralismo jurídico y alternatividad judicial. El Otro Derecho, Issue 26-27, pp. 63-98.

Esther, Comandanta (2001), "Discurso ante la tribuna del Congreso de la Unión" en Enlace Zapatista. Disponi- ble en: https://enlacezapatista.ezln.org. $\mathrm{mx} / 2001 / 03 / 28 /$ discurso-de-la-comandanta-esther-en-la-tribuna-del-congresode-la-union/ [10 de septiembre de 2019]

EZLN (1996), "La Cuarta Declaración de la Selva Lacandona" en Enlace Zapatista. Disponible en: http://enlacezapatista.ezln. org.mx/1996/01/01/cuarta-declaracionde-la-selva-lacandona/ [18 mayo 2019].

Institute for Economics \& Peace (2019), Índice de Paz de México: Identificar y medir los factores que impulsanla paz, Sidney: Institute for Economics \& Peace. Disponible en: http://visionofhumanity.org/app/ uploads/2019/04/MPI-ESP-2019-Reportweb.pdf [13 de junio de 2019]

Leticia, Gloria (2019), "México tiene cifras de muertes violentas propias de un país en guerra: Bachelet" en Proceso. Disponible en: https://www.proceso.com. mx/578949/mexico-tiene-cifras-demuertes-violentas-propias-de-un-pais-enguerra-bachelet [10 de junio 2019]

Leyva, Xochitl (2008), "Investigación Social y Pueblos Indígenas: ¿en dónde estamos, de dónde venimos y hacia dónde vamos?", en Bastos, Santiago (comp.), Multiculturalismo y futuro en Guatemala, Guatemala, FLACSO/OXFAM, pp. 175-215.

Marcos, Subcomandante (1994), "Historia de las preguntas" en Enlace Zapatista. Disponible en: https://enlacezapatista.ezln. org.mx/1994/12/13/la-historia-de-las-preguntas/ [20 de septiembre de 2019]

Marcos, Subcomandante Insurgente (2017), Escritos sobre la guerra y la economía política, México, Pensamiento Crítico Ediciones.

Maurer, Eugenio (1984), Los Tseltales, ¿paganos o cristianos? Su religión ¿sincretismo o síntesis?, México, Centro de Estudios Educativos.

Mora, Mariana (2018), Política Kuxlejal: Autonomía indígena, el Estado racial e in- 
vestigación descolonizante en comunidades zapatistas, Ciudad de México, CIESAS. Rosillo, Alejandro y De la Torre, Jesús (2009), Acuerdos de San Andrés. Texto, estudio introductorio, comentarios y referencias, México, Comisión Estatal de Derechos Humanos de San Luis Potosíl Facultad de Derecho de la Universidad Autónoma de San Luis Potosí/ CENEJUS/CRT. Santos, Boaventura de Sousa (2004), Reinventar la democracia, Quito, Abya Yala.

Santos, Boaventura de Sousa (2009), Sociología Jurídica Crítica. Para un nuevo sentido común en el derecho, Madrid, Trotta/ILSA.

Sierra, Ma Teresa (1997), "Esencialismo y autonomía: paradojas de las reivindicaciones indígenas", Revista Alteridades, Issue 14, México, UAM-I, pp. 131-143.

Sierra, Ma Teresa (2015), "La renovación de la justicia indígena en tiempos de derechos: etnicidad, género y diversidad "en Lillas. Visiting Resource Professor Papers, Texas: The University of Texas at Austin. Disponible en: https://repositories.lib. utexas.edu/handle/2152/4104 [10 de mayo de 2019]

Sierra, Ma Teresa, Rosalva A. Hernández y Rachel Sieder (eds.) (2013), Justicias Indígenas y Estado. Violencias contemporáneas, México: FLACSO-CIESAS.

Valencia, Sayak (2010), Capitalismo Gore, España, Melusina.

Vargas, Rosa, E. (2019), "Intelectuales apoyan al EZLN y rechazan calumnias" en La Jornada. Disponible en: https:// www. jornada.com.mx/ultimas/politica/2019/01/16/intelectuales-apoyan-alezln-y-rechazan-calumnias-6598.html [20 de septiembre de 2019]

Wallerstein, Immanuel (2001), "Marcos, Mandela y Gandhi" en La Jornada. Disponible en: https://www.rebelion.org/heme- roteca/opinion/031014wallerstein.htm [13 de junio de 2019]

Yrigoyen Fajardo, Raquel (1999), Pautas de coordinación entre el derecho indígena y el derecho estatal, Guatemala, Fundación Myrna Mack. 